\title{
Proven and potential clinical benefits of washing red blood cells before transfusion: current perspectives
}

This article was published in the following Dove Press journal:

International Journal of Clinical Transfusion Medicine

22 August 2016

Number of times this article has been viewed

\section{Amy E Schmidt \\ Majed A Refaai \\ Scott A Kirkley \\ Neil Blumberg}

Department of Pathology and Laboratory Medicine, University of Rochester Medical Center, Rochester, NY, USA
Correspondence: Amy E Schmidt Department of Pathology and Laboratory Medicine, University of Rochester Medical Center, 60I Elmwood Avenue, Box 608, Rochester, NY 14642, USA

$\mathrm{Tel}+\mathrm{I} 5852753189$

Fax +I 5852733003

Email amy_schmidt@urmc.rochester.edu
Abstract: Red blood cells (RBCs) are washed for a variety of reasons such as to remove excess potassium, cytokines, and other allergen proteins from the supernatant and/or to mitigate the effects of the storage lesion. The storage lesion is a product of RBC aging and include leakage of potassium and chloride from the RBCs, depletion of 2,3-diphosphoglycerate and adenosine triphosphate, loss of phospholipids and cholesterol, exposure of phosphatidylserine, elaboration of lipid mediators, loss of glutathione, autoxidation of hemoglobin to methemoglobin contributing to decreased blood flow viscosity and adherence to endothelial cells, increased microparticle formation, and disruption of NO-mediated vasodilation. A storage lesion is thought to be caused in part by oxidative stress, which is characterized by functional and structural changes to the RBCs. The effects of the RBC storage lesion on patient morbidity and mortality have been studied intensively with mixed results. Here, we will summarize the potential benefits of RBC washing. Notably, all patient-based studies on washed RBCs are single-center, small randomized studies or observational data, which await replication and tests of generalizability. Some of the most promising preliminary data suggest that washed transfusions of red cells and platelets reduce mortality in low risk, younger patients with acute myeloid leukemia, mitigate lung injury, and substantially reduce mortality in cardiac surgery. Larger randomized trials to replicate or refute these findings are urgently needed and, most importantly, have the potential to strikingly improve clinical outcomes following transfusion.

Keywords: washed blood, transfusion, immunomodulation, red blood cell

\section{Introduction}

Blood transfusions are among the most common procedures performed in hospitals. ${ }^{1}$ They entail risks such as transfusion-related acute lung injury (TRALI), transfusionassociated graft versus host disease, transfusion-associated circulatory overload, immunomodulation, inflammation, infection, and thrombosis. ${ }^{2-13}$ The effect of the storage age of red blood cells (RBCs) on patient morbidity and mortality has been the subject of numerous studies with contradictory findings. ${ }^{14-27}$ As blood ages, the RBCs develop a "storage lesion" that includes leakage of potassium and chloride from the RBCs, depletion of 2,3-diphosphoglycerate and adenosine triphosphate, loss of phospholipids and cholesterol, exposure of phosphatidylserine, elaboration of lipid mediators, loss of glutathione, autoxidation of hemoglobin to methemoglobin, decreased blood flow viscosity and adherence to endothelial cells, increased microparticle formation, and disruption of nitric oxide (NO)-mediated vasodilation. ${ }^{28-34}$ Free hemoglobin, heme and iron, some within microparticles, may be significant mediators of toxicity. The 
storage lesion is hypothesized to be due, at least in part, to oxidative stress, which causes functional and structural changes to the RBCs. ${ }^{35-38}$

One of the primary causes of febrile nonhemolytic transfusion reactions (FNHTRs) are cytokines produced by white blood cells (WBCs). ${ }^{39}$ The rate of FNHTRs has substantially decreased following widespread implementation of leukoreduction; however, there are still some WBCs remaining in the blood products and WBC-derived cytokines increase as the blood product ages. ${ }^{39}$ Some of the cytokines and chemokines that have been shown to increase during storage of RBCs and platelets are interleukin (IL)-1 $\beta$, IL-6, IL-8, and tumor necrosis factor- $\alpha .{ }^{40}$ Notably, these cytokines and chemokines have been implicated in FNHTRs. Other cytokines and chemokines have also been shown to accumulate such as RANTES (regulated on activation, normal T cell expressed and secreted; CCL5), which is associated with allergic transfusion reactions; ${ }^{41}$ soluble CD40 ligand (sCD40L), which induces proinflammatory mediators such as IL-6, IL-8, and MCP-1 and may be associated with TRALI; ${ }^{10,12}$ and Fas ligand and TGF- $\beta$, which may contribute to transfusion-related immune modulation. ${ }^{42,43}$ A recent study by Muszynski et $\mathrm{al}^{44}$ showed that soluble mediators in the RBC supernatant from 30-day $\mathrm{RBC}$ units induced monocyte suppression in transfusion recipients. This group has previously observed that critically ill children have a suppressed monocyte function following transfusion of RBC units stored for long periods of time. ${ }^{45,46}$ Thus, longer stored RBC units have been shown to accumulate various chemokines and cytokines that contribute to a variety of different types of transfusion reactions.

Three large randomized clinical trials investigated the effects of storage age of blood on recipient morbidity and mortality: Age of Blood Evaluation (ABLE), Red-Cell Storage Duration Study (RECESS), and Age of Red Blood Cells in Premature Infants (ARIPI). The ABLE study conducted at 64 locations in Canada and Europe and evaluated 90-day mortality in critically ill patients receiving fresh $(<8$ days old) versus longer stored RBCs (mean of 22 days old). No differences in the 90-day mortality between the two groups were detected. ${ }^{47}$ The RECESS conducted at multiple centers across the US examined clinical outcomes following cardiac surgery in patients ( $>12$ years old) who received fresh RBCs ( $<10$ days old) versus older RBCs ( $>21$ days old). This study did not detect any statistically significant differences in Multiple Organ Dysfunction Scores, 7-day or 28-day mortality. ${ }^{48}$ The ARIPI trial was conducted at six tertiary neonatal intensive care units in Canada and examined length of stay, nosocomial infections, and organ dysfunction in 377 premature infants weighing $<1,250 \mathrm{~g}$ who received fresher blood ( $<7$ days old) versus standard issued blood (mean of 14.6 days old). No statistically significant differences were also found in the measured outcomes between both groups. ${ }^{49}$ Thus, these three large trials support that on average RBC age has little-to-no effect on outcome. However, these studies do not fully address the safety of transfusion of red cells near the end of storage (eg, 35-42 days) because few patients in these trials received transfusion of such longer stored red cells.

Among others, a large multicenter study, the Age of Blood in Children in Pediatric Intensive Care Units (ABC PICU) study, is ongoing. This randomized clinical trial is enrolling 1,538 children and comparing development of new or progressive multiple organ dysfunction syndrome in critically ill children transfused with either RBCs stored $\leq 7$ days or standard issued RBCs (expected mean storage duration of 17-21 days). ${ }^{50}$ Thus, the question of the effect of RBC age on patient morbidity and mortality is still of concern to many clinicians. Particularly important, none of these studies included patients receiving large doses of much longer stored red cells (eg, $>28$ days or $>35$ days). This is relevant because there are robust epidemiologic and observational data indicating that such longer stored RBC may indeed be associated with increased morbidity and mortality, particularly in vulnerable populations such as infants undergoing cardiac surgery. ${ }^{51,52}$

One potential approach to mitigating the $\mathrm{RBC}$ storage lesion is to wash the RBC unit and remove most accumulated mediators, free hemoglobin, microparticles, etc. RBC washing is commonly done for patients with repeated allergic or febrile transfusion reactions; however, it is not routinely available at many medical centers. This review will focus on the potential and hypothesized benefits of washing RBC units prior to transfusion.

\section{EFFECT of RBC storage lesion on blood transfusion}

As mentioned earlier, the storage lesion refers to molecules and other products that accumulate in stored RBCs as they age. Washing of RBCs removes much of what accumulates in stored RBCs such as microparticles and free hemoglobin. Additionally, washing also removes the RBC storage solution as well as additive solution, plasma proteins, and some of the contaminating WBCs, platelets, and cellular debris. The question is what effects have these substances been shown to have on blood transfusion? Remy et a ${ }^{53}$ have written an excellent review on the influence of the storage lesion on pediatric transfusion; however, the overall effects on RBC 
transfusion will be discussed below. D'Alessandro et $\mathrm{al}^{36,54}$ have shown that older RBCs have decreased antioxidant activity and impaired energy metabolism. Proteolytic enzymes and kinases become activated leading to modification of Band 3 and other RBC structural proteins that result in $\mathrm{RBC}$ cytoskeletal remodeling. This remodeling was shown to result in increased osmotic fragility, increased shedding of microparticles, and RBC morphologic changes. ${ }^{36,54} \mathrm{~A}$ recent study looked at $\mathrm{RBC}$ deformability before and after transfusion in 16 patients undergoing spinal fusion surgery. $\mathrm{RBC}$ deformability was found to be significantly decreased following transfusion in patients receiving $\geq 5$ units of RBCs. Elongation index measured by ektacytometry decreased by $12 \% \pm 4 \%$ to $20 \% \pm 6 \%, P=0.03$ as compared to patients receiving $0-4 \mathrm{RBC}$ units $(3 \% \pm 1 \%$ to $4 \% \pm 1 \%, P=0.68)$. Notably, these changes did not reverse when measured 3 days postoperatively. Additional studies have shown that as RBCs age, they develop an increasing oxidative environment, which results in fatty acid oxidation and other oxidation metabolites. ${ }^{36,54,55}$ Similarly, after 14 days, the RBCs have impaired energy metabolism. ${ }^{36,54,55}$ A recent study of 34 patients undergoing spinal fusion examined oxidative stress as measured by the presence of fluorescent heme degradation products and methemoglobin as measured by spectrophotometric methods as a function of RBC storage time. In this study, oxidative stress was found to increase as storage time increased $(R=0.54, P=0.032) .{ }^{56}$ Additionally, oxidative stress was also higher in stored RBCs as compared to fresh RBCs (9.1 \pm 10.3 vs $7.7 \pm 0.9$ fluorescent arbitrary units; $P<0.001) .{ }^{56} \mathrm{RBC}$ deformability was also found to decrease with increased storage time $(R=-0.60, P=0.009) .{ }^{56}$ Using a proteomics approach, D'Alessandro et $\mathrm{al}^{57}$ showed that as RBCs age, free hemoglobin is released into the supernatant as well as glyceraldehyde-3-phosphate dehydrogenase, peroxiredoxin-1, -2 , and -6 , carbonic anhydrase- 1 and -2 , selenium binding protein-1, biliverdin reductase, aminolevulinate dehydratase, and catalase. Older RBCs contain a large number of hemolyzed RBCs and free iron. Animal studies have shown that transfusion of old RBCs results in a bolus of free iron, which results in oxidative damage and potentiates bacterial proliferation. ${ }^{58,59}$ Sarachana et $\mathrm{a}^{60}$ have shown that several small noncoding RNAs in stored RBCs have levels that correlate with cell death, adenosine triphosphate loss, and changes in RBC indices.

To date, there have been $>50$ observational clinical studies of transfusion in humans, which have been excellently reviewed by Qu and Triulzi. ${ }^{14}$ Notably, some of these studies have shown that RBCs stored for longer periods of time are associated with increased risk of sepsis, multiorgan failure, myocardial infarction, thrombosis, pneumonia, and death. However, others showed no effect of RBC storage age on any of these outcomes, which illustrates uncertainty.

\section{RBC washing}

Washing process of RBCs is typically performed by normal saline $(0.9 \% \mathrm{NaCl})$ in either an open or a closed system. The washing procedure removes $\sim 95 \%-99 \%$ of the RBC supernatant, which contains in addition to the additive solution, plasma proteins, electrolytes, some WBCs, platelets, microparticles, and cellular debris. ${ }^{13,61}$ RBCs washed in an open system should be used within 24 hours postwashing due to the theoretical increased risk for bacterial contamination, as well as RBC viability in normal saline. ${ }^{62} \mathrm{RBC}$ s washed in a closed system have an expiration time of 14 days. ${ }^{62}$ There have been no observed differences in the safety and efficacy of $\mathrm{RBC}$ washed in the closed system with extended expiration versus the open system. ${ }^{63} \mathrm{RBC}$ washing is frequently used in neonates and infants undergoing cardiac surgery. One important reason for this practice is the reduction in extracellular potassium that once transfused can cause hyperkalemia in the patients. ${ }^{64,65}$ Notably, Masalunga et al ${ }^{65}$ studied saline washed versus unwashed RBCs and the effect on neonatal extracorporeal membrane oxygenation (ECMO). They found that washing reduced the extracellular potassium but increased the RBC membrane osmotic fragility, which led to increased hemolysis of the washed RBCs within the first 3 days of ECMO ${ }^{65}$ The benefits of washing RBCs have been attributable to both elimination of toxic accumulations of substances such as free hemoglobin and potassium in the supernatant and removal of the more fragile cells. However, $\mathrm{RBC}$ washing may also increase the RBC osmotic fragility, leading to increased hemolysis following transfusion. ${ }^{34,65}$

Bennett-Guerrero et $\mathrm{al}^{61}$ washed 40 units of 40-42-dayold RBCs using two different washing devices, the Cobe 2991 (Terumo BCT, Lakewood, CO, USA) and the Haemonetics Cell Saver Elite (Haemonetics, Braintree, MA, USA). The Cobe 2991 is a device used in a variety of procedures for washing and concentrating cellular components and is typically used in the setting of a blood bank. The Haemonetics Cell Saver Elite is a point-of-care device used for processing autologous shed blood typically used during operating room procedures. Both devices effectively removed the extracellular potassium and other toxic substances from the supernatant and recovered a significant number of starting 
RBCs. ${ }^{61}$ The levels of plasma-free hemoglobin, hemolysis, and $\mathrm{RBC}$ microparticle production were found to be higher in RBC units washed using the Haemonetics Cell Saver Elite. ${ }^{61}$ Thus, depending on the washing device used, it is possible that washing RBC units may cause additional damage.

$\mathrm{RBC}$ washing is not widely available. Many smaller and medium-sized hospital blood banks do not have a cell washer available. Additionally, some blood banks do not hold an FDA permit to modify blood products, which would preclude them from washing RBCs. In addition to the widespread lack of availability of RBC washers, the RBC washing process takes $\sim 1.5-2$ hours. This delays RBC availability and precludes use of washed RBCs in cases of emergency and in massive transfusion protocols. RBC washing also requires increased technologist time to prepare the RBC unit and widespread use of $\mathrm{RBC}$ washing could necessitate increased FTEs in the blood bank. As noted earlier, most RBC washers used are open systems and thus the washed RBC units have an expiration of 24 hours. This shortened life span could generate increased RBC wastage and cost if the washed units are not used prior to expiration.

Reinhart et $\mathrm{al}^{66}$ studied the effect of washing RBCs in $1 \%$ albumin solution versus normal saline, buffer, or plasma to determine if the RBC echinocyte shape change that develops during storage could be reversed or improved. They found that washing in 1\% albumin decreased the proportion of echinocytes and increased the proportion of discocytes. They also observed a decrease in RBC swelling with albumin washing. These improvements were not observed when the RBCs were washed in normal saline, buffer, or plasma. Notably, the RBC shape normalization following washing in $1 \%$ albumin did not improve RBC deformability as measured by ektacytometry; however, it did improve the perfusion of an artificial microvascular network. ${ }^{66}$ Thus, washing may be able to improve the shape changes caused by RBC storage for prolonged periods. Further studies are needed evaluating different washing solutions. Normal saline has been reported in preliminary data to increase hemolysis during washing compared with a balanced salt solution (Plasma-Lyte A). ${ }^{67}$

\section{Washing RBCs and leukoreduction}

WBCs in blood products are an important cause of transfusion complications, FNHTRs, platelet refractoriness, CMV transmission, and postoperative nosocomial infections. As described previously, the rate of WBC-derived proinflammatory cytokines increases over the storage period. ${ }^{68-71}$ Notably, transfused WBCs may be the target of recipient antibodies that can stimulate the WBCs to release cytokines. Universal leukoreduction has many benefits including reduction of FNHTRs, ${ }^{72-74}$ decreased platelet refractoriness caused by alloimmunization against leukocyte antigens, ${ }^{75-77}$ decreased transmission of $\mathrm{CMV},{ }^{78,79}$ and decreased postoperative infections. $^{80,81}$

A study by Aston et $\mathrm{al}^{82}$ examined whether additional washing of leukoreduced RBC units would reduce production of human leukocyte antigen (HLA)-specific antibodies in children with chronic kidney disease. They studied 106 children and found no difference in HLA sensitization risk between patients receiving nonwashed leukodepleted RBC and patients receiving washed leukodepleted units $(P=0.32) .{ }^{82}$ They hypothesized that this lack of difference was attributable to the small amount of leukocytes that remained after washing, as washing removed only $\sim 33 \%$ of the small number of leukocytes that were present. 82

Universal leukoreduction has also been shown to decrease the risk of transfusion-related immunomodulation. ${ }^{83}$ Animal and human studies have shown that allogeneic blood products cause downregulation of cellular immunity and dysregulation of inflammatory innate immunity. ${ }^{84}$ The majority of data support that the storage supernatant is a large contributor to transfusion-related immunomodulation. Several studies have shown that transfused RBCs affect the perioperative release of inflammatory mediators in cardiac surgery patients. ${ }^{85}$ Similarly, studies have shown that washed RBCs are superior to unwashed RBCs when fresh RBC are not available for children undergoing cardiopulmonary bypass. ${ }^{86} \mathrm{~A}$ randomized trial in adults with leukemia has shown that patients receiving washed, leukoreduced, ABO identical products had substantially improved survival (approximately a halving of mortality, $P=0.014$ ) as compared to patients receiving unwashed, leukoreduced, and $\mathrm{ABO}$ identical products. ${ }^{11,87}$ These results have been replicated in our center after implementation of universal washing for younger patients with acute myeloid leukemia (unpublished data). Additionally, Cholette et $\mathrm{al}^{88}$ found that children undergoing cardiac surgery who received washed, leukoreduced blood products had lower levels of inflammatory markers when compared to children receiving unwashed, leukoreduced products, and a trend toward reduced mortality.

\section{RBC washing and neonates}

Preterm infants typically suffer from anemia of prematurity due to a multitude of reasons, including decreased levels of plasma erythropoietin, decreased RBC lifespan, blood loss due to phlebotomy, and decreased transport of iron due to premature birth. ${ }^{89}$ Several studies in neonates indicated that 
$\mathrm{RBC}$ transfusions may be related to necrotizing enterocolitis, chronic lung disease, intraventricular hemorrhage, retinopathy of prematurity, and death..$^{90-95}$ The ARIPI trial examined whether RBCs stored for $<7$ days as compared to the standard of care decreased rates of infection or organ dysfunction in infants with birth weights $<1,250 \mathrm{~g} .^{49}$ The ARIPI investigators found that the mean age of transfused blood was 5.1 days in the fresh RBC group ( $\mathrm{n}=188$ ) and 14.6 days in the standard group $(n=189)$. The rate of necrotizing enterocolitis, retinopathy of prematurity, bronchopulmonary dysplasia, intraventricular hemorrhage, and death was similar among neonates in the fresh RBC group ( $\mathrm{n}=99,52.7 \%)$ compared with the standard $\mathrm{RBC}$ group $(\mathrm{n}=100,52.9 \%)$. The rate of clinically suspected infection was also similar in the fresh RBC group $77.7 \%(n=146)$ compared with $77.2 \%(n=146)$ in the standard RBC group. ${ }^{49}$ The lack of difference observed may have been due to the small difference in the age of the blood studied (5.1 days vs 14.6 days). RBCs typically do not expire until 35 days (CPDA-1) or 42 days (AS), and relatively young $\mathrm{RBC}$ units were used in this study. Only a small number of patients received significant amounts of longer stored red cells.

Notably, other transfusion reactions such as TRALI may be underrecognized and underreported in the neonatal population. ${ }^{96,97}$ One possible explanation for these associations with RBC transfusion is the "two hit" model of posttransfusion injury proposed by Aiboshi et al. ${ }^{98}$ In this model, a preexisting inflammatory state primes the neonates' immune system and a subsequent RBC transfusion triggers immune cell activation and immunomodulation. Several studies have suggested that leukoreduced RBCs can cause endothelial cell activation, oxidative stress, and inflammation in neonates. ${ }^{99,100}$ Thus, washing $\mathrm{RBC}$ units in $0.9 \%$ normal saline or another replacement fluid would be expected to reduce these effects and improve outcomes in neonates and other population.

\section{RBC washing in pediatrics and adults}

As stored RBCs age, free hemoglobin and microparticle concentrations increase. Several studies have suggested that exposure of patients to these two moieties during and following transfusion may contribute to adverse events. ${ }^{34,101-104}$ One study in septic patients showed that free plasma hemoglobin was an independent predictor of mortality. ${ }^{105}$ Several studies have evaluated the effects of washing RBCs in different patient populations. Blumberg et $\mathrm{al}^{11,87}$ have studied typespecific washed RBC and platelets versus unwashed RBC and platelets in adults with acute leukemia. They observed a striking improvement in outcome in those receiving washed RBC and platelet transfusions. ${ }^{11,87}$ In this observational cohort study no mortality was observed at 30 days, 60 days, and 100 days in the washed recipients $<46$ years of age compared with the local historical control group receiving unwashed transfusions $(4 \%, 7 \%$, and $9 \% ; P=0.14,0.05$, and 0.018 , respectively). When restricted to a more homogeneous subset of AML patients $<46$ years of age with favorable or standard cytogenetics, long-term mortality was $60 \%$ in the comparison group (and in the current literature) and 20\% in the recipients of washed transfusions (unpublished data). These results are without precedent and warrant larger randomized controlled trials to assess these preliminary findings.

The abovementioned study by Cholette et $\mathrm{al}^{88}$ also found that patients receiving washed products had less systemic inflammation and relatively a better survival rate (two deaths in the washed group vs six deaths in the unwashed group). Notably, washing of older RBCs ( $>27$ days) was found to be associated with both a higher infection rate and an increased morbidity as compared with unwashed RBCs. ${ }^{52}$ Again, larger multicenter trials are needed to further evaluate these findings. Jy et $\mathrm{al}^{106}$ conducted a prospective randomized study of washed versus unwashed RBC transfusions in 148 adult patients undergoing coronary artery bypass graft. They found no differences in patient clinical or comorbidity data and also no differences in serious adverse events. However, the patients receiving unwashed transfusions had higher inhospital mortality (4 vs 0 ) and higher 1-year postoperative mortality ( 7 vs 0 ). Moreover, the frequency of less serious adverse events was also higher in the patients receiving unwashed transfusions. ${ }^{106}$

\section{Washing RBCs and transfusion reactions}

Washing of RBCs has been shown in several studies to reduce and prevent transfusion reactions. Crews et $\mathrm{al}^{107}$ reported that washing of RBCs was an effective measure in preventing acute hypotensive transfusion reactions in patients unable to metabolize vasodilators present in the donor unit. Similarly, Blumberg et al ${ }^{83,108}$ reported that over a 14 -year period, the incidence of transfusion-associated circulatory overload and TRALI at a large academic medical center ( $>800$ bed) was eleven out of 319,161 leukoreduced nonwashed and zero out of 97,445 leukoreduced washed RBC and platelet products. Notably, they also reported that the incidence of febrile transfusion reactions to leukoreduced washed platelets 
is close to zero as compared to $1 \%-2 \%$ in the leukoreduced nonwashed platelet transfusions. ${ }^{83}$

\section{Washing RBCs and trauma}

Several observational studies have suggested that transfusion of longer stored RBCs is linked to increased incidences of acute lung injury, acute kidney injury, pneumonia, and mortality in trauma bleeding patients. ${ }^{109-112}$ The underlying hypothesis is that the older RBCs once transfused, scavenge NO in an iron/heme-dependent manner. ${ }^{30,113,114}$ Additionally, the older RBCs are believed to be less effective at stimulating endogenous NO formation. ${ }^{113,114}$ Thus, NO homeostasis is lost. ${ }^{30,113,114}$ In a canine model, washing of stored canine RBCs has been shown to prevent infectious lung injury in addition to other side effects. ${ }^{115}$ Similarly, a study by Stapley et al, ${ }^{114}$ which evaluated $\mathrm{RBC}$ washing in a mouse trauma-hemorrhage model, found that washing 10-day stored red cells protected against its lethality, which was $\sim 90 \%$ without washing. Notably, they also found that transfusion with free heme partially restored the toxicity of the older washed RBCs. ${ }^{114}$ Additionally, they found that inhibition of TLR4 signaling, administration of TAK-242, or hemopexin-dependent sequestration of free heme decreased the storage age-dependent lethality of the RBCs. ${ }^{114}$ These two animal studies suggest that part of the storage lesion toxicity of RBCs is likely attributable to the disruption of NO homeostasis. Additional studies in humans are needed to further evaluate this phenomenon. Finally, in one negative study and for unclear reason, washing did not abrogate the deleterious effect of red cell transfusion in a mouse model of inflammation. ${ }^{116}$ The investigators proposed that membraneencapsulated hemoglobin is required to produce inflammation as there was no inflammatory response to transfusions of either membrane ghosts or stroma-free lysate derived from the stored RBCs. It is possible that the RBCs studied had a low level of bacterial contamination that was not detected despite culturing the cells. However, the investigators did trial injecting the cells with lipopolysaccharides and found a different cytokine profile, making this less likely. ${ }^{116}$

\section{Future directions}

As detailed earlier, there have been very few studies looking at the benefits, risks, and effects of washing RBCs. Additionally, there have been even fewer clinical trials to explore washed RBC usage. A search of clinicaltrials.gov in June 2016 showed several studies on washed RBCs to be ongoing and actively recruiting. Thus, hopefully, some answers will soon be available. The Mayo Clinic, Duke University, and Blood Systems Research Institute have an ongoing study (NCT02094118) that is examining pointof-care washing of allogeneic leukoreduced RBCs to see whether this treatment reduces pulmonary complications in cardiac surgery patients. Seoul National University Bundang Hospital is actively engaged in another study (NCT01934907) in which patients with various orthopedic hip problems such as avascular necrosis, etc are receiving washed RBCs and they are examining the hypothesis that washed units can decrease transfusion complications. In another study at Duke University (NCT02485366), researchers are investigating whether rejuvenated, washed RBCs improve outcomes in children undergoing cardiac surgery. Similarly, at Duke University, researchers are investigating the use of Rejuvesol ${ }^{\circledR}$ treated and washed RBCs in sickle cell patients (NCT02731157). Researchers at the University of Miami along with the NHLBI (NCT01185600) are comparing washed RBCs that have microparticles removed to unwashed RBCs with microparticles and examining the differences in endothelial disturbances, inflammatory responses, and procoagulant responses. The last ongoing study of washed RBCs is our own study at the University of Rochester (NCT01976442), which examines the outcomes of adult acute leukemia patients treated with washed RBCs. Thus, in the next few years, hopefully, these studies will yield more detailed answers regarding the benefits, risks, and effects of washing RBCs. It is still quite likely that questions will still remain, and additional studies are needed.

\section{Authors' point of view}

It is our point of view that washed RBCs are beneficial to certain patient populations under certain circumstances. We do not advocate for universal use of washed RBCs as this is cost prohibitive, time consuming, and not feasible under many circumstances such as acute bleeding and MTPs. We have found clinical benefit in using washed RBCs in adult acute leukemia patients $<50$ years of age. Additionally, we have found clinical benefit in using washed RBCs in patients who have had repeated febrile transfusion reactions. Similarly, patients with IgA deficiency receive washed RBCs. We also provide washed RBCs (first unit) to all pediatric cardiac patients when a bypass pump is being used. We have sufficient staffing to be able to wash the required units in a timely fashion and rarely expire washed products. Thus, we do propose and believe that washed RBC products 
have clinical benefit. We do acknowledge that more studies are needed and that little is known as to why washed RBCs provide a benefit to certain patient populations over unwashed RBCs.

\section{Conclusion}

The previous sections have detailed the numerous studies that have evaluated RBC washing in humans and animals. These studies suggest that washing of RBCs is safe and can sometimes effectively mitigate allogeneic storage lesion effects due to supernatant and perhaps enhance the proportion of normal RBCs. The majority of RBC washing is performed with normal saline and as described previously, additional studies are needed to evaluate other washing solutions such as buffered physiologic salt solutions and $1 \%$ albumin, which may be less toxic to both red cells and patients. Finally, the studies described previously suggest the likelihood that washed RBCs can reduce inflammation, morbidity, and mortality in some clinical settings. However, larger randomized clinical trials are needed to replicate and further evaluate these preliminary findings.

\section{Disclosure}

The authors report no conflicts of interest in this work.

\section{References}

1. HCUP. HCUP Facts and Figures: Statistics on Hospital-Based Care in the United States, 2009. Rockville, MD: HCUP; 2011.

2. Popovsky MA, Moore SB. Mechanism of transfusion-related acute lung injury. Blood. 1991;77(10):2299.

3. Tartter PI, Mohandas K, Azar P, Endres J, Kaplan J, Spivack M. Randomized trial comparing packed red cell blood transfusion with and without leukocyte depletion for gastrointestinal surgery. Am J Surg. 1998;176(5):462-466.

4. Tartter PI, Quintero S, Barron DM. Perioperative blood transfusion associated with infectious complications after colorectal cancer operations. Am J Surg. 1986;152(5):479-482.

5. van Hilten JA, van de Watering LM, van Bockel JH, et al. Effects of transfusion with red cells filtered to remove leucocytes: randomised controlled trial in patients undergoing major surgery. $B M J$. 2004;328(7451):1281.

6. Rao SV, Jollis JG, Harrington RA, et al. Relationship of blood transfusion and clinical outcomes in patients with acute coronary syndromes. JAMA. 2004;292(13):1555-1562.

7. Nilsson KR, Berenholtz SM, Garrett-Mayer E, Dorman T, Klag MJ, Pronovost PJ. Association between venous thromboembolism and perioperative allogeneic transfusion. Arch Surg. 2007;142(2):126-132. [discussion 33].

8. Khorana AA, Francis CW, Blumberg N, Culakova E, Refaai MA, Lyman GH. Blood transfusions, thrombosis, and mortality in hospitalized patients with cancer. Arch Intern Med. 2008;168(21): 2377-2381.

9. van de Watering LM, Hermans J, Houbiers JG, et al. Beneficial effects of leukocyte depletion of transfused blood on postoperative complications in patients undergoing cardiac surgery: a randomized clinical trial. Circulation. 1998;97(6):562-568.
10. Blumberg N, Gettings KF, Turner C, Heal JM, Phipps RP. An association of soluble CD40 ligand (CD154) with adverse reactions to platelet transfusions. Transfusion. 2006;46(10):1813-1821.

11. Blumberg N, Heal JM, Liesveld JL, Phillips GL, Rowe JM. Platelet transfusion and survival in adults with acute leukemia. Leukemia. 2008;22(3):631-635.

12. Khan SY, Kelher MR, Heal JM, et al. Soluble CD40 ligand accumulates in stored blood components, primes neutrophils through CD40, and is a potential cofactor in the development of transfusion-related acute lung injury. Blood. 2006;108(7):2455-2462.

13. Grimshaw K, Sahler J, Spinelli SL, Phipps RP, Blumberg N. New frontiers in transfusion biology: identification and significance of mediators of morbidity and mortality in stored red blood cells. Transfusion. 2011;51(4):874-880.

14. Qu L, Triulzi DJ. Clinical effects of red blood cell storage. Cancer Control. 2015;22(1):26-37.

15. Aubron C, Nichol A, Cooper DJ, Bellomo R. Age of red blood cells and transfusion in critically ill patients. Ann Intensive Care. 2013;3(1):2.

16. Lelubre C, Vincent JL. Relationship between red cell storage duration and outcomes in adults receiving red cell transfusions: a systematic review. Crit Care. 2013;17(2):R66.

17. Eikelboom JW, Cook RJ, Liu Y, Heddle NM. Duration of red cell storage before transfusion and in-hospital mortality. Am Heart J. 2010;159(5):737.e-743.e.

18. Heddle NM, Eikelboom J, Liu Y, Barty R, Cook RJ. Exploratory studies on the age of transfused blood and in-hospital mortality in patients with cardiovascular diagnoses. Transfusion. 2015;55(2):364-372.

19. Spinella PC, Carroll CL, Staff I, et al. Duration of red blood cell storage is associated with increased incidence of deep vein thrombosis and in hospital mortality in patients with traumatic injuries. Crit Care. 2009;13(5):R151.

20. Katsios C, Griffith L, Spinella P, et al. Red blood cell transfusion and increased length of storage are not associated with deep vein thrombosis in medical and surgical critically ill patients: a prospective observational cohort study. Crit Care. 2011;15(6):R263.

21. Dunn LK, Thiele RH, Ma JZ, Sawyer RG, Nemergut EC. Duration of red blood cell storage and outcomes following orthotopic liver transplantation. Liver Transpl. 2012;18(4):475-481.

22. Cywinski JB, You J, Argalious M, et al. Transfusion of older red blood cells is associated with decreased graft survival after orthotopic liver transplantation. Liver Transpl. 2013;19(11):1181-1188.

23. Kekre N, Mallick R, Allan D, Tinmouth A, Tay J. The impact of prolonged storage of red blood cells on cancer survival. PLoS One. 2013;8(7):e68820.

24. Manlhiot C, McCrindle BW, Menjak IB, et al. Longer blood storage is associated with suboptimal outcomes in high-risk pediatric cardiac surgery. Ann Thorac Surg. 2012;93(5):1563-1569.

25. Min JJ, Bae JY, Kim TK, et al. Association between red blood cell storage duration and clinical outcome in patients undergoing off-pump coronary artery bypass surgery: a retrospective study. BMC Anesthesiol. 2014;14:95.

26. Kinnunen EM, Sabatelli L, Juvonen T, Biancari F. Red blood cell storage time and the outcome after coronary surgery. J Surg Res. 2015;197(1):58-64.

27. van de Watering L, Lorinser J, Versteegh M, Westendord R, Brand A. Effects of storage time of red blood cell transfusions on the prognosis of coronary artery bypass graft patients. Transfusion. 2006;46(10):1712-1718.

28. Hess JR. Red cell changes during storage. Transfus Apher Sci. 2010;43(1):51-59.

29. Yalcin O, Ortiz D, Tsai AG, Johnson PC, Cabrales P. Microhemodynamic aberrations created by transfusion of stored blood. Transfusion. 2014;54(4):1015-1027.

30. Stapley R, Owusu BY, Brandon A, et al. Erythrocyte storage increases rates of $\mathrm{NO}$ and nitrite scavenging: implications for transfusion-related toxicity. Biochem J. 2012;446(3):499-508. 
31. Alexander JT, El-Ali AM, Newman JL, et al. Red blood cells stored for increasing periods produce progressive impairments in nitric oxide-mediated vasodilation. Transfusion. 2013;53(11):2619-2628.

32. Tissot JD, Rubin O, Canellini G. Analysis and clinical relevance of microparticles from red blood cells. Curr Opin Hematol. 2010;17(6):571-577.

33. Silliman CC, Moore EE, Kelher MR, Khan SY, Gellar L, Elzi DJ. Identification of lipids that accumulate during the routine storage of prestorage leukoreduced red blood cells and cause acute lung injury. Transfusion. 2011;51(12):2549-2554.

34. Donadee C, Raat NJ, Kanias T, et al. Nitric oxide scavenging by red blood cell microparticles and cell-free hemoglobin as a mechanism for the red cell storage lesion. Circulation. 2011;124(4):465-476.

35. D'Alessandro A, D'Amici GM, Vaglio S, Zolla L. Time-course investigation of SAGM-stored leukocyte-filtered red bood cell concentrates: from metabolism to proteomics. Haematologica. 2012;97(1):107-115.

36. D'Alessandro A, Kriebardis AG, Rinalducci S, et al. An update on red blood cell storage lesions, as gleaned through biochemistry and omics technologies. Transfusion. 2015;55(1):205-219.

37. Kim-Shapiro DB, Lee J, Gladwin MT. Storage lesion: role of red blood cell breakdown. Transfusion. 2011;51(4):844-851.

38. Bosman GJ, Werre JM, Willekens FL, Novotny VM. Erythrocyte ageing in vivo and in vitro: structural aspects and implications for transfusion. Transfus Med. 2008;18(6):335-347.

39. Rajesh K, Harsh S, Amarjit K. Effects of prestorage leukoreduction on the rate of febrile nonhemolytic transfusion reactions to red blood cells in a tertiary care hospital. Ann Med Health Sci Res. 2015;5(3):185-188.

40. Nagura Y, Tsuno NH, Tanaka M, Matsuhashi M, Takahashi K. The effect of pre-storage whole-blood leukocyte reduction on cytokines/ chemokines levels in autologous CPDA-1 whole blood. Transfus Apher Sci. 2013;49(2):223-230.

41. Wakamoto S, Fujihara M, Kuzuma K, et al. Biologic activity of RANTES in apheresis PLT concentrates and its involvement in nonhemolytic transfusion reactions. Transfusion. 2003;43(8):1038-1046.

42. Ghio M, Contini P, Mazzei C, et al. Soluble HLA class I, HLA class II, and Fas ligand in blood components: a possible key to explain the immunomodulatory effects of allogeneic blood transfusions. Blood. 1999;93(5):1770-1777.

43. Hodge GL, Hodge SJ, Nairn J, Tippett E, Holmes M, Reynolds PN. Poststorage leuko-depleted plasma inhibits T-cell proliferation and Th1 response in vitro: characterization of TGFbeta-1 as an important immunomodulatory component in stored blood. Transplantation. 2005;80(1):95-101.

44. Muszynski JA, Bale J, Nateri J, et al. Supernatants from stored red blood cell (RBC) units, but not RBC-derived microvesicles, suppress monocyte function in vitro. Transfusion. 2015;55(8):1937-1945.

45. Muszynski JA, Nofziger R, Greathouse K, et al. Innate immune function predicts the development of nosocomial infection in critically injured children. Shock. 2014;42(4):313-321.

46. Muszynski JA, Frazier E, Nofziger R, et al. Red blood cell transfusion and immune function in critically ill children: a prospective observational study. Transfusion. 2015;55(4):766-774.

47. Lacroix J, Hebert PC, Fergusson DA, et al. Age of transfused blood in critically ill adults. $N$ Engl J Med. 2015;372(15):1410-1418.

48. Steiner ME, Ness PM, Assmann SF, et al. Effects of red-cell storage duration on patients undergoing cardiac surgery. $N$ Engl J Med. 2015;372(15):1419-1429.

49. Fergusson DA, Hebert P, Hogan DL, et al. Effect of fresh red blood cell transfusions on clinical outcomes in premature, very low-birth-weight infants: the ARIPI randomized trial. JAMA. 2012;308(14):1443-1451.

50. ClinicalTrials.gov [webpage on the Internet]. Age of Blood in Children in Pediatric Intensive Care Units (ABC PICU). Available from: https:// clinicaltrials.gov/ct2/show/NCT01977547. Accessed August 9, 2016.

51. Goel R, Johnson DJ, Scott AV, et al. Red blood cells stored 35 days or more are associated with adverse outcomes in high-risk patients. Transfusion. 2016;56(7):1690-1698.
52. Cholette JM, Pietropaoli AP, Henrichs KF, et al. Longer RBC storage duration is associated with increased postoperative infections in pediatric cardiac surgery. Pediatr Crit Care Med. 2015;16(3):227-235.

53. Remy KE, Natanson C, Klein HG. The influence of the storage lesion(s) on pediatric red cell transfusion. Curr Opin Pediatr. 2015;27(3):277-285.

54. D'Alessandro A, Nemkov T, Kelher M, et al. Routine storage of red blood cell (RBC) units in additive solution-3: a comprehensive investigation of the RBC metabolome. Transfusion. 2015;55(6):1155-1168.

55. Delobel J, Prudent M, Rubin O, Crettaz D, Tissot JD, Lion N. Subcellular fractionation of stored red blood cells reveals a compartment-based protein carbonylation evolution. J Proteomics. 2012;76(Spec No):181-193.

56. Nagababu E, Scott AV, Johnson DJ, et al. Oxidative stress and rheologic properties of stored red blood cells before and after transfusion to surgical patients. Transfusion. 2016;56(5):1101-1111.

57. D'Alessandro A, Dzieciatkowska M, Hill RC, Hansen KC. Supernatant protein biomarkers of red blood cell storage hemolysis as determined through an absolute quantification proteomics technology. Transfusion. 2016;56(6):1329-1339.

58. Hod EA, Spitalnik SL. Harmful effects of transfusion of older stored red blood cells: iron and inflammation. Transfusion. 2011;51(4):881-885.

59. Spitalnik SL. Stored red blood cell transfusions: iron, inflammation, immunity, and infection. Transfusion. 2014;54(10):2365-2371.

60. Sarachana T, Kulkarni S, Atreya CD. Evaluation of small noncoding RNAs in ex vivo stored human mature red blood cells: changes in noncoding RNA levels correlate with storage lesion events. Transfusion. 2015;55(11):2672-2683.

61. Bennett-Guerrero E, Kirby BS, Zhu H, Herman AE, Bandarenko N, McMahon TJ. Randomized study of washing 40- to 42-day-stored red blood cells. Transfusion. 2014;54(10):2544-2552.

62. AABB. Standards for Blood Banks and Transfusion Services. 30th ed. Bethesda, MD: AABB; 2015.

63. Acker JP, Hansen AL, Yi QL, et al. Introduction of a closed-system cell processor for red blood cell washing: postimplementation monitoring of safety and efficacy. Transfusion. 2016;56(1):49-57.

64. Moore GL, Peck CC, Sohmer PR, Zuck TF. Some properties of blood stored in anticoagulant CPDA-1 solution. A brief summary. Transfusion. 1981;21(2):135-137.

65. Masalunga C, Cruz M, Porter B, Roseff S, Chui B, Mainali E. Increased hemolysis from saline pre-washing RBCs or centrifugal pumps in neonatal ECMO. J Perinatol. 2007;27(6):380-384.

66. Reinhart WH, Piety NZ, Deuel JW, et al. Washing stored red blood cells in an albumin solution improves their morphologic and hemorheologic properties. Transfusion. 2015;55(8):1872-1881.

67. Kirkley SA, Henrichs KF, Schmidt AE, et al. Decreased hemolysis of red cells washed with plasma-lyte as compared with $0.9 \%$ sodium chloride. American Society of Hematology (ASH); December 4-8, 2015; Orlando, FL.

68. Muylle L, Joos M, Wouters E, De Bock R, Peetermans ME. Increased tumor necrosis factor alpha (TNF alpha), interleukin 1, and interleukin 6 (IL-6) levels in the plasma of stored platelet concentrates: relationship between TNF alpha and IL-6 levels and febrile transfusion reactions. Transfusion. 1993;33(3):195-199.

69. Muylle L, Peetermans ME. Effect of prestorage leukocyte removal on the cytokine levels in stored platelet concentrates. Vox Sang. 1994;66(1):14-17.

70. Aye MT, Palmer DS, Giulivi A, Hashemi S. Effect of filtration of platelet concentrates on the accumulation of cytokines and platelet release factors during storage. Transfusion. 1995;35(2):117-124.

71. Ferrer F, Rivera J, Corral J, Gonzalez-Conejero R, Lozano ML, Vicente V. Evaluation of pooled platelet concentrates using prestorage versus poststorage WBC reduction: impact of filtration timing. Transfusion. 2000;40(7):781-788.

72. Yazer MH, Podlosky L, Clarke G, Nahirniak SM. The effect of prestorage WBC reduction on the rates of febrile nonhemolytic transfusion reactions to platelet concentrates and RBC. Transfusion. 2004;44(1):10-15. 
73. Federowicz I, Barrett BB, Andersen JW, Urashima M, Popovsky $\mathrm{MA}$, Anderson KC. Characterization of reactions after transfusion of cellular blood components that are white cell reduced before storage. Transfusion. 1996;36(1):21-28.

74. King KE, Shirey RS, Thoman SK, Bensen-Kennedy D, Tanz WS, Ness PM. Universal leukoreduction decreases the incidence of febrile nonhemolytic transfusion reactions to RBCs. Transfusion. 2004;44(1):25-29.

75. Seftel MD, Growe GH, Petraszko T, et al. Universal prestorage leukoreduction in Canada decreases platelet alloimmunization and refractoriness. Blood. 2004;103(1):333-339.

76. Mishima Y, Tsuno NH, Matsuhashi M, et al. Effects of universal vs bedside leukoreductions on the alloimmunization to platelets and the platelet transfusion refractoriness. Transfus Apher Sci. 2015;52(1):112-121.

77. [No authors listed]. Leukocyte reduction and ultraviolet B irradiation of platelets to prevent alloimmunization and refractoriness to platelet transfusions. The Trial to Reduce Alloimmunization to Platelets Study Group. N Engl J Med. 1997;337(26):1861-1869.

78. Dzik WH. Leukoreduction of blood components. Curr Opin Hematol. 2002;9(6):521-526.

79. Kopko PM, Holland PV. Universal leukocyte reduction. Curr Opin Hematol. 2000;7(6):397-401.

80. Fergusson D, Khanna MP, Tinmouth A, Hebert PC. Transfusion of leukoreduced red blood cells may decrease postoperative infections: two meta-analyses of randomized controlled trials. Can J Anaesth. 2004;51(5):417-424.

81. Blumberg N, Zhao H, Wang H, Messing S, Heal JM, Lyman GH. The intention-to-treat principle in clinical trials and meta-analyses of leukoreduced blood transfusions in surgical patients. Transfusion. 2007;47(4):573-581.

82. Aston A, Cardigan R, Bashir S, et al. Washing red cells after leucodepletion does not decrease human leukocyte antigen sensitization risk in patients with chronic kidney disease. Pediatr Nephrol. 2014;29(10):2005-2011.

83. Lannan KL, Sahler J, Spinelli SL, Phipps RP, Blumberg N. Transfusion immunomodulation - the case for leukoreduced and (perhaps) washed transfusions. Blood Cells Mol Dis. 2013;50(1):61-68.

84. Blumberg N, Heal JM. Immunomodulation by blood transfusion: an evolving scientific and clinical challenge. Am J Med. 1996;101(3):299-308.

85. Fransen E, Maessen J, Dentener M, Senden N, Buurman W. Impact of blood transfusions on inflammatory mediator release in patients undergoing cardiac surgery. Chest. 1999;116(5):1233-1239.

86. Bansal I, Calhoun BW, Joseph C, Pothiawala M, Baron BW. A comparative study of reducing the extracellular potassium concentration in red blood cells by washing and by reduction of additive solution. Transfusion. 2007;47(2):248-250.

87. Blumberg N, Heal JM, Rowe JM. A randomized trial of washed red blood cell and platelet transfusions in adult acute leukemia [ISRCTN76536440]. BMC Blood Disord. 2004;4(1):6.

88. Cholette JM, Henrichs KF, Alfieris GM, et al. Washing red blood cells and platelets transfused in cardiac surgery reduces postoperative inflammation and number of transfusions: results of a prospective, randomized, controlled clinical trial. Pediatr Crit Care Med. 2012;13(3):290-299.

89. Venkatesh V, Khan R, Curley A, Hopewell S, Doree C, Stanworth S. The safety and efficacy of red cell transfusions in neonates: a systematic review of randomized controlled trials. Br J Haematol. 2012; 158(3):370-385.

90. Mohamed A, Shah PS. Transfusion associated necrotizing enterocolitis: a meta-analysis of observational data. Pediatrics. 2012;129(3):529-540.

91. Cooke RW, Drury JA, Yoxall CW, James C. Blood transfusion and chronic lung disease in preterm infants. Eur J Pediatr. 1997;156(1):47-50.

92. Baer VL, Lambert DK, Henry E, Snow GL, Butler A, Christensen $\mathrm{RD}$. Among very-low-birth-weight neonates is red blood cell transfusion an independent risk factor for subsequently developing a severe intraventricular hemorrhage? Transfusion. 2011;51(6):1170-1178.
93. Giannantonio C, Papacci P, Cota F, et al. Analysis of risk factors for progression to treatment-requiring ROP in a single neonatal intensive care unit: is the exposure time relevant? JMatern Fetal Neonatal Med. 2012;25(5):471-477.

94. dos Santos AM, Guinsburg R, de Almeida MF, et al. Red blood cell transfusions are independently associated with intra-hospital mortality in very low birth weight preterm infants. J Pediatr. 2011;159(3):.e1-. e3.

95. Valieva OA, Strandjord TP, Mayock DE, Juul SE. Effects of transfusions in extremely low birth weight infants: a retrospective study. $J$ Pediatr. 2009;155(3):331-337.e1.

96. Gauvin F, Robillard P, Hume H, et al. Transfusion-related acute lung injury in the Canadian paediatric population. Paediatr Child Health. 2012;17(5):235-239.

97. Rashid N, Al-Sufayan F, Seshia MM, Baier RJ. Post transfusion lung injury in the neonatal population. J Perinatol. 2013;33(4):292-296.

98. Aiboshi J, Moore EE, Ciesla DJ, Silliman CC. Blood transfusion and the two-insult model of post-injury multiple organ failure. Shock. 2001;15(4):302-306.

99. Keir AK, McPhee AJ, Andersen CC, Stark MJ. Plasma cytokines and markers of endothelial activation increase after packed red blood cell transfusion in the preterm infant. Pediatr Res. 2013;73(1):75-79.

100. Stark MJ, Keir AK, Andersen CC. Does non-transferrin bound iron contribute to transfusion related immune-modulation in preterms? Arch Dis Child Fetal Neonatal Ed. 2013;98(5):F424-F429.

101. Reynolds JD, Ahearn GS, Angelo M, Zhang J, Cobb F, Stamler JS. S-nitrosohemoglobin deficiency: a mechanism for loss of physiological activity in banked blood. Proc Natl Acad Sci U S A. 2007;104(43): 17058-17062.

102. Reynolds JD, Bennett KM, Cina AJ, et al. S-nitrosylation therapy to improve oxygen delivery of banked blood. Proc Natl Acad Sci USA. 2013;110(28):11529-11534.

103. Zhu H, Zennadi R, Xu BX, et al. Impaired adenosine-5'-triphosphate release from red blood cells promotes their adhesion to endothelial cells: a mechanism of hypoxemia after transfusion. Crit Care Med. 2011;39(11):2478-2486.

104. Belizaire RM, Prakash PS, Richter JR, et al. Microparticles from stored red blood cells activate neutrophils and cause lung injury after hemorrhage and resuscitation. JAm Coll Surg. 2012;214(4):648-655. [discussion 56-57].

105. Janz DR, Bastarache JA, Peterson JF, et al. Association between cellfree hemoglobin, acetaminophen, and mortality in patients with sepsis: an observational study. Crit Care Med. 2013;41(3):784-790.

106. Jy W, Gomez-Marin O, Salerno TA, et al. Transfusion with washed vs. unwashed packed red cells in coronary artery bypass graft (CABG) surgery: major outcome differences. American Society of Hematology; December 6-9, 2014; San Francisco, CA.

107. Crews WS Jr, Kay JK, Herman JH. Washed RBCs prevent recurrent acute hypotensive transfusion reactions. Am J Clin Pathol. 2014;141(2):285-287.

108. Blumberg N, Heal JM, Gettings KF, et al. An association between decreased cardiopulmonary complications (transfusion-related acute lung injury and transfusion-associated circulatory overload) and implementation of universal leukoreduction of blood transfusions. Transfusion. 2010;50(12):2738-2744.

109. Weinberg JA, Barnum SR, Patel RP. Red blood cell age and potentiation of transfusion-related pathology in trauma patients. Transfusion. 2011;51(4):867-873.

110. Weinberg JA, McGwin G Jr, Griffin RL, et al. Age of transfused blood: an independent predictor of mortality despite universal leukoreduction. J Trauma. 2008;65(2):279-282. [discussion 82-84].

111. Weinberg JA, McGwin G Jr, Marques MB, et al. Transfusions in the less severely injured: does age of transfused blood affect outcomes? J Trauma. 2008;65(4):794-798.

112. Weinberg JA, McGwin G Jr, Vandromme MJ, et al. Duration of red cell storage influences mortality after trauma. JTrauma. 2010;69(6):14271431. [discussion 31-32]. 
113. Liu C, Liu X, Janes J, et al. Mechanism of faster NO scavenging by older stored red blood cells. Redox Biol. 2014;2:211-219.

114. Stapley R, Rodriguez C, Oh JY, et al. Red blood cell washing, nitrite therapy, and antiheme therapies prevent stored red blood cell toxicity after trauma-hemorrhage. Free Radic Biol Med. 2015;85: 207-218.
115. Cortes-Puch I, Wang D, Sun J, et al. Washing older blood units before transfusion reduces plasma iron and improves outcomes in experimental canine pneumonia. Blood. 2014;123(9):1403-1411.

116. Hod EA, Zhang N, Sokol SA, et al. Transfusion of red blood cells after prolonged storage produces harmful effects that are mediated by iron and inflammation. Blood. 2010;115(21):4284-4292.
International Journal of Clinical Transfusion Medicine

\section{Publish your work in this journal}

International Journal of Clinical Transfusion Medicine is an international, peer-reviewed, open access, online journal publishing clinicalexperimental, policy-making and evidence-based practices of all topics pertaining to clinical transfusion medicine. Original research, short reports, reviews, case reports and commentaries are invited.
Dovepress

The manuscript management system is completely online and includes a very quick and fair peer-review system, which is all easy to use. Visit http://www.dovepress.com/testimonials.php to read real quotes from published authors.

Submit your manuscript here: https://www.dovepress.com/international-journal-of-clinical-transfusion-medicine-journal 